\title{
Code 2: Emotional and Sexual Concerns Post-surgery
}

There was a general all around consensus that erectile dysfunction care was lacking significantly, and the requirement for this may be significantly worse in younger men and those in a single relationship (Table 47.1).

- 'The emotional impact is related to personal circumstances, especially if younger.'-ID2

- 'My cancer was aggressive and nerves were removed. There is a lack of care for $E D-$ The recovery may be time related.'-ID2

- 'For younger people under the age of 60, this ED care needs to be standard.'

- 'The age of cancer is getting younger, with fertility problems.'-ID 3

Additionally, it was felt that in patients from an ethnic minority, psychosexual care treatment requirements were not significantly met. This again clearly highlighted the need for a pathway to deliver this care. There is a clear lack of psychosexual care demonstrated here, with acknowledgement of this problem as a significant issue. There was also a great deal of self-awareness within this group that the age of diagnosis is getting younger and that services need to be able to manage this. A pathway of care would draw together and address all these needs.

Table 47.1 Code 2: Emotional and sexual concerns post-surgery

\begin{tabular}{l|l}
\hline & Patient quotes using Patient Identification Numbers \\
\hline $\begin{array}{l}\text { Age and gender } \\
\text { related issues }\end{array}$ & $\begin{array}{l}\text { 'The emotional impact is related to personal circumstances, especially } \\
\text { if younger.'-ID 1 }\end{array}$ \\
\hline $\begin{array}{l}\text { Requirement for } \\
\text { Tailored Care }\end{array}$ & $\begin{array}{l}\text { 'Patients who are at different stages have different requirements for } \\
\text { ED. This is impacted on by the extent of surgery.'-ID3 }\end{array}$ \\
\hline $\begin{array}{l}\text { Lack of } \\
\text { psychosexual care }\end{array}$ & 'We need a specialist in ED. It needs to be taken seriously.'-ID4 \\
\hline $\begin{array}{l}\text { Lack of ED care } \\
\text { Ethnicity issues }\end{array}$ & $\begin{array}{l}\text { 'The cancer is treated very well, not ED.'-ID5 } \\
\text { 'We lack the proper medicines for ED and a serious medical approach, } \\
\text { especially in the Afro-Caribbean population.'-ID1 } \\
\text { 'In an Afro-Caribbean culture, patients would rather die than suffer ED.' ID1 }\end{array}$ \\
\hline
\end{tabular}

